\title{
Genetic Parameters of Growth in Dairy Cattle and Associations Between Growth and Health Traits
}

\author{
S. Brotherstone,${ }^{\star} \dagger^{1}$ M. P. Coffey, $\dagger$ and G. Banos \\ *School of Biological Sciences, University of Edinburgh, Ashworth Laboratories, King's Buildings, Edinburgh, EH9 3JT, United Kingdom \\ †Sustainable Livestock Systems Group, Scottish Agricultural College, Bush Estate, Penicuik, Midlothian, EH26 OPH, United Kingdom \\ ‡Department of Animal Production, School of Veterinary Medicine, Box 393, Aristotle University of Thessaloniki, \\ GR-54124 Thessaloniki, Greece
}

\begin{abstract}
Body weight (BW) observations on dairy cattle taken on average 35 times between birth and 1,000 d of life were used to estimate daily heritabilities and predict daily breeding values for both pregnancy-adjusted BW (PABW) and growth rate. Daily heritabilities for PABW were moderate to high, ranging from $0.41( \pm 0.027)$ to $0.82( \pm 0.041)$. Daily heritabilities for growth rate were high $(>0.68 \pm 0.034)$. The genetic association between various health events, including mastitis and lameness, and weight and growth was investigated by regressing the incidence of health events on breeding values for weight at birth, weaning, calving, and growth rate at $56 \mathrm{~d}$ after calving, growth rate at $110 \mathrm{~d}$ after calving, and maximum growth rate. Growth at weaning was the only BW measure to significantly affect mastitis $\left(\mathrm{r}_{\mathrm{g}}=\right.$ $0.24)$, indicating that cows growing faster at weaning are more prone to mastitis. Increased weight $\left(\mathrm{r}_{\mathrm{g}}=0.65\right)$ and growth rate at weaning $\left(r_{g}=0.38\right)$ and increased maximum growth rate $\left(r_{g}=0.71\right)$ all contributed to increased feet disorders. The only significant negative genetic association was obtained between reproduction and weight at calving $\left(r_{g}=-0.61\right)$.
\end{abstract}

Key words: body weight, growth rate, health event

\section{INTRODUCTION}

Reduced feed and housing costs for smaller, lighter cows result in them being more profitable than larger, heavier cows at equal production level and ignoring any other associations between size and profitability. This is recognized by a number of countries throughout the world that include body size, with a negative weighting, in their national selection index for Holsteins (Miglior et al., 2005). Visscher et al. (1994) also derived a negative economic value for mature BW in pasture-based systems and concluded that the inclusion of BW in the

Received April 17, 2006.

Accepted August 29, 2006

${ }^{1}$ Corresponding author: S.Brotherstone@ed.ac.uk breeding goal could prevent BW from increasing as production increases.

In general, researchers have derived a negative genetic correlation between BW and milk production (Veerkamp and Thompson, 1999; Abdallah and McDaniel, 2000; Veerkamp et al., 2000), although both positive and negative correlations have been estimated. In a review of research into feed intake and utilization, Veerkamp (1998) quoted genetic correlations between live weight and milk yield ranging from -0.41 to +0.45 . He suggested that the change in correlation is related to the time of weighing (or definition of the weight trait) and reflects the mobilization of body tissue to meet the demands of increased yield. The genetic correlation between BW change and yield was, however, found to be high and negative in all studies reviewed (Veerkamp, 1998). That review also presented estimates of the heritability of BW obtained from a number of studies but pointed out that generally these estimates are subject to large sampling errors.

A study by Hansen et al. (1999) found that cows in a small (body size) line required fewer services to conception during first lactation than did cows in a large (body size) line. Berry et al. (2003) estimated the genetic correlation between $\mathrm{BW}$ at a number of days during first lactation and various fertility measures and showed that although genetically heavier cows are served sooner, they require more services and have a longer interval from first service to conception.

Veerkamp (1998) concluded that although there appears to be great potential to improve economic efficiency by selecting for feed intake and BW, there is uncertainty about genetic associations with traits related to health and reproduction. These associations are required if $\mathrm{BW}$ is to be included in an index containing production measures and traits related to longevity and health.

In addition to BW at specific points in a cow's life, her growth rate during early life may have a significant impact on her health in later life. Research has demonstrated the economic benefits of calving dairy heifers for the first time at 24 mo of age (Hoffman and Funk, 
1992; Mourits et al., 1997) but dairy cows are not mature at this age and continue to grow throughout first lactation. Coffey et al. (2006) concluded that cows selected to be of high genetic merit for milk production grew faster in early life than those of average genetic merit, whereas the growth rate of the average genetic merit cows was higher during first lactation. Mäntysaari et al. (2002) also found that genetic selection for milk yield leads to higher genetic potential for growth. They suggest that this needs to be accounted for in recommendations of acceptable daily gains for young heifers.

The objectives of this work were (1) to estimate daily heritabilities and breeding values for BW, (2) to calculate heritabilities and breeding values for growth rate from the relevant values for BW, and (3) to investigate any genetic associations between $\mathrm{BW}$ and growth rate at various points in a cow's early life and health events during first lactation.

\section{MATERIALS AND METHODS}

\section{BW Data}

Data comprised 21,763 BW records taken from birth to $1,000 \mathrm{~d}$ of life, on 625 cows. These cows were part of the Langhill herd, which comprises a control line of cows of average genetic merit and a select line of cows of high genetic merit, with approximately equal numbers in each group. The animals were reared from birth to first calving as a single management group and at first calving, half of each group was assigned to a high concentrate feed group and the rest to a low concentrate feed group. Weights were taken at birth, weaning (mean age at weaning was $48.9 \mathrm{~d}$ with a standard deviation of $6.35 \mathrm{~d}$ ), first winter, spring turnout, mid summer and subsequent housing, then second winter, turnout, and summer. After first calving, cows were weighed weekly. Depending on time of birth, young stock may not have all weight records but on average there were 35 records per cow.

Before analysis, all BW records of pregnant heifers were adjusted for the predicted weight of the conceptus and gravid uterus (Coffey et al., 2006). Throughout this article, PABW refers to pregnancy-adjusted live weight. The relevant pedigree file of 5,393 animals was also extracted from the Langhill database.

\section{Analysis of BW Data}

Pregnancy-adjusted BW was analyzed using the following random regression animal model:

$$
\begin{aligned}
& y_{l m}=y w_{i}+g_{j}+f_{k}+(g f)_{j k}+\sum_{n=1}^{2} a_{n} a g e^{n} \\
& +\sum_{n=0}^{5} b_{j n} m^{n}+\sum_{n=0}^{3} c_{l n} m^{n}+\sum_{n=0}^{1} d_{l n} m^{n}+e_{l m}
\end{aligned}
$$

where $Y_{l m}=\mathrm{PABW}$ record of cow 1 recorded on day of life $\mathrm{m}, \mathrm{yw}_{\mathrm{i}}=$ fixed effect of year-week of measurement $\mathrm{i}, \mathrm{g}_{\mathrm{j}}=$ fixed effect of selection line $\mathrm{j}, \mathrm{f}_{\mathrm{k}}=$ fixed effect of feeding group $\mathrm{k},(\mathrm{gf})_{\mathrm{jk}}=$ interaction between genetic line and feed group, $a_{n}=$ regression coefficient on age at calving (age), $b_{j n}=$ fixed regression coefficient associated with the overall PABW curve for cows in genetic line $\mathrm{j}$; that is, a separate overall trend curve was fitted for each genetic line, $c_{\mathrm{ln}}=$ random regression coefficient associated with the additive genetic effect of cow $1, d_{l n}=$ random regression coefficients associated with the permanent environment effect of cow $\mathrm{l}$, and $\mathrm{e}_{\mathrm{lm}}=$ random residual term. The degree of the fixed regression was based on the significance of the regression coefficients, whereas the degree of the random genetic regression was based on likelihood ratio tests. The random permanent environmental effect was modeled as a linear regression because models with higher order regressions failed to converge. Thirteen measurement error classes were defined based on Coffey et al. (2006). Error variance was assumed to be homogeneous within classes and heterogeneous between classes.

The analysis of PABW provides all the parameters needed to estimate daily heritability of PABW, but to estimate daily heritability for growth rate, an estimate of the genetic and phenotypic variance of growth rate is needed. The latter comprises genetic plus permanent environmental variance plus an estimate of measurement error variance.

Let $\mathrm{c}=\left[1 \mathrm{~m} \mathrm{~m}^{2} \mathrm{~m}^{3}\right]$ represent the vector of base functions (as above, $m$ is days of life) and $G$ represent the 4 by 4 matrix of (co)variances between the random coefficients of PABW. The genetic variance of PABW for each day of life can then be estimated as c $G c^{\prime}$ (Kirkpatrick et al., 1990), where $c^{\prime}$ is the transpose of $c$.

If growth rate is considered as the change in PABW from day $m$ to day $(m+1)$, then divided differences can be used to estimate the genetic variance for each day. The live weight of cow $\mathrm{l}$ at day $\mathrm{m}$ is $\mathrm{c}_{10}+\mathrm{c}_{11} \mathrm{~m}+\mathrm{c}_{12} \mathrm{~m}^{2}$ $+\mathrm{c}_{13} \mathrm{~m}^{3}$ and her live weight at day $(\mathrm{m}+1)$ is $\mathrm{c}_{10}+\mathrm{c}_{11}(\mathrm{~m}+1)$ $+c_{12}(m+1)^{2}+c_{13}(m+1)^{3}$. Growth rate is the difference between live weight at day $(m+1)$ and live weight at day $m$ and is therefore equal to $c_{11}+(1+2 m) c_{12}+(1+$

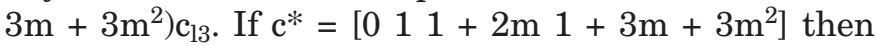
the genetic variance of growth rate for each day of life can be estimated as $\mathrm{c}^{*} \mathrm{Gc}^{* \prime}$, where $\mathrm{c}^{* \prime}$ is the transpose of $c^{*}$. Similarly, the contribution of the permanent environmental variance to the phenotypic variance is 
merely the variance of the slope $d_{1}$. Because measurements were taken $1 \mathrm{~d}$ apart, the contribution of the measurement error variance to the phenotypic variance of growth rate was $2^{*} \sigma^{2}$ e, where $\sigma^{2}$ is the appropriate measurement error variance (see Results section for further details on estimating the measurement error variance).

The analysis of PABW data yielded a cubic genetic $\mathrm{PABW}$ curve and a quadratic genetic growth rate curve for each cow, both expressed as deviations from overall trend curves. For each cow, breeding values for birth, weaning and calving weights, rate of growth at weaning, first calving, $56 \mathrm{~d}$ after first calving (approximately peak yield), $110 \mathrm{~d}$ after first calving (average day at pregnancy), and maximum growth rate were calculated.

\section{Health Data}

Because this investigation concentrated on growth from birth to d 1,000 (i.e., approximate end of first lactation), only first-lactation health events were considered. Health events were well recorded on these cows by technical staff trained in animal recording, and veterinary staff. Health events considered were mastitis, other teat and udder problems (e.g., teat blockage, difficult milking), reproductive disorders (e.g., ruptured uterus, retained placenta), metabolic disorders including gastrointestinal infection, ketosis, and Salmonella, foul feet (also known as foot rot), lameness, and other feet problems (e.g., digital dermatitis, sole lesion). Each category of health event was analyzed separately.

The base data set was taken as those 625 cows with PABW records. Cows culled during first lactation have a reduced opportunity to experience health events. We therefore deleted cows that survived less than $927 \mathrm{~d}$ (the average age at first calving of $727 \mathrm{~d}$ plus $200 \mathrm{~d}$, which is the minimum lactation length that qualifies for official publication), and also deleted 2 cows with missing birth weights. The final data set comprised 513 cows. Of these, 459 experienced at least one incidence of a health event during first lactation.

\section{Analysis of Health Data}

The model used was:

$$
\begin{aligned}
y_{i}=g_{j}+f_{k} & +(g f)_{j k}+y b_{l}+\sum_{n=1}^{2} a_{n} a g e^{n} \\
& +b_{m} w_{m}+e_{i}
\end{aligned}
$$

where $y_{i}$ is the count of the number of health events in each category experienced by cow i during first lacta- tion, $g_{j}$ is the fixed effect of selection line $j, f_{k}$ is the fixed effect of feeding group $\mathrm{k}$ and $\mathrm{yb}_{1}$ is the fixed effect of year of birth $1, a_{1}$ and $a_{2}$ are regression coefficients on age at calving (age) and age squared, and $b_{m}(m=$ 1 to 8) are the linear regression coefficients of each health event on breeding values $\left(\mathrm{w}_{\mathrm{m}}\right)$ for birth weight, weaning weight, calving weight, growth rate at weaning, growth rate at calving, growth rate $56 \mathrm{~d}$ after calving, growth rate at $110 \mathrm{~d}$ after calving and maximum growth rate, fitted one at a time ( $m$ runs) so that $b_{1}$ to $b_{8}$ were not expressed relative to other measures of weight or growth coefficients. The random residual term is represented by $\mathrm{e}_{\mathrm{i}}$. All analyses were performed 1) with a linear model assuming normally distributed health traits, 2) with a log link function assuming a Poisson distribution, and 3) using a square root transformation.

Regressing phenotypic health observations on genetic merit for weight and growth traits gives approximate genetic regressions (Brotherstone and Hill, 1991; Pryce et al., 2000). These can be expressed as genetic correlations as follows:

$$
r_{G}=b \cdot \frac{\sigma_{1}}{\sigma_{2}}
$$

where $r_{G}=$ the estimated genetic correlation, $b=$ each of the regression coefficients $\left(b_{1}, b_{2}, \ldots b_{m}\right)$ calculated from model 2 , and $\sigma_{1}$ and $\sigma_{2}=$ the genetic standard deviation estimates for the relevant weight trait and health trait. Genetic standard deviations for the weight traits and phenotypic variances for the health traits were taken from this analysis. The heritabilities for mastitis and reproductive disorders were estimated from a genetic analysis of these data, but as the genetic variance for other feet disorders was not significantly different from zero, an average literature value for the heritability was used. The incidence of metabolic disorders was so low that results for this trait are not presented.

\section{RESULTS AND DISCUSSION}

Summary statistics for the PABW data have been given by Coffey et al. (2006) but for completeness, the number of records, means and standard deviations for each measurement error class, together with residual error variances are in Table 1. Mean PABW increased throughout the period under investigation with the highest residual error variance, and poorest fit of the model to the data, taking place in the 200-d period before first calving (days of life 500 to 729). This is in agreement with previous analyses of these data (Coffey et al., 2006) and could be due to the fact that measurement error variances before and around first calving 
Table 1. Number of records in each of the 13 residual error classes and the corresponding phenotypic mean $(\mathrm{kg})$, standard deviation (SD), and residual error variances (REV) for pregnancy-adjusted BW for all cows for days of life 0 through 1,000

\begin{tabular}{lccrr}
\hline & Records & $\begin{array}{l}\text { Mean } \\
\text { (kg) }\end{array}$ & \multicolumn{1}{c}{ SD } & \multicolumn{1}{c}{$\begin{array}{l}\text { REV } \\
\left(\mathrm{kg}^{2}\right)\end{array}$} \\
\hline Birth to d 36 & 622 & 43.4 & 4.93 & 8.20 \\
Weaning (d 36 to 69) & 625 & 69.8 & 8.38 & 36.5 \\
d 100 to 199 & 300 & 188.8 & 24.45 & 195.4 \\
d 200 to 299 & 672 & 240.4 & 31.75 & 120.3 \\
d 300 to 399 & 490 & 329.0 & 37.74 & 172.3 \\
d 400 to 499 & 588 & 398.3 & 40.66 & 332.4 \\
d 500 to 729 & 2,023 & 496.2 & 49.17 & 669.3 \\
d 730 to 739 & 442 & 519.1 & 43.48 & 512.7 \\
d 740 to 749 & 531 & 520.9 & 45.10 & 473.6 \\
d 750 to 759 & 563 & 522.7 & 43.39 & 334.8 \\
d 760 to 789 & 1,872 & 528.5 & 44.31 & 250.4 \\
d 790 to 889 & 6,497 & 545.8 & 48.87 & 135.6 \\
d 890 to 1,000 & 6,538 & 554.2 & 54.18 & 204.1 \\
\hline
\end{tabular}

are based on the estimated pregnancy-adjusted live weight of both pregnant and nonpregnant cows.

Figure 1 gives the overall trend curves for PABW for the select and control lines. These curves are based on the solutions for the fixed curves from model 1 and hence are adjusted for all other effects in the model. As found by Coffey et al. (2006), select cows are significantly heavier than control cows from shortly after birth until around the time of first calving. From about d 730 (first calving) onward, control cows are heavier than select cows and have a higher growth rate (Figure 2). This is consistent with the work of Abdallah and McDaniel (2000), who found that genetically, higher producing cows had lower breeding values than lower producing cows for predicted BW after calving, and with the results of Coffey et al. (2004), who reported that the select cows in this data set lost more PABW after first calving than their control line herdmates.

Variances of the variance components and covariances between them were used to estimate the standard

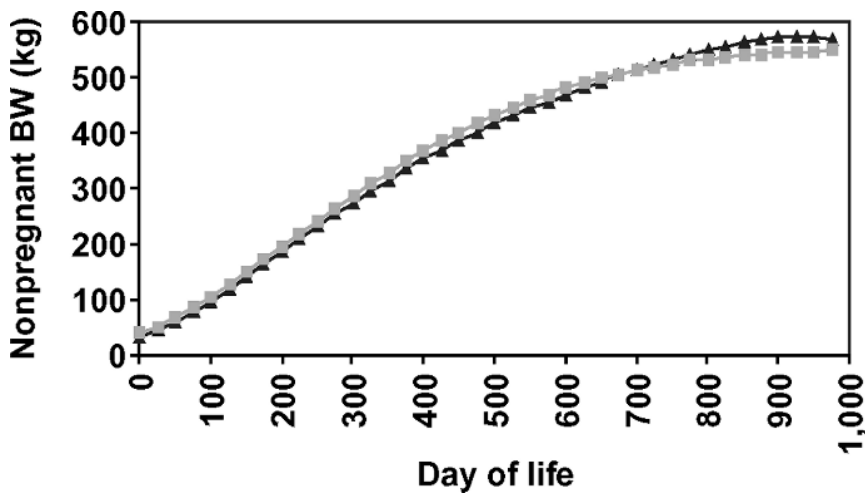

Figure 1. Pregnancy-adjusted BW (kg) for each day of life from birth to d 1,000 for select ( $\mathbf{\square})$ and control ( $\mathbf{\Delta})$ cows.

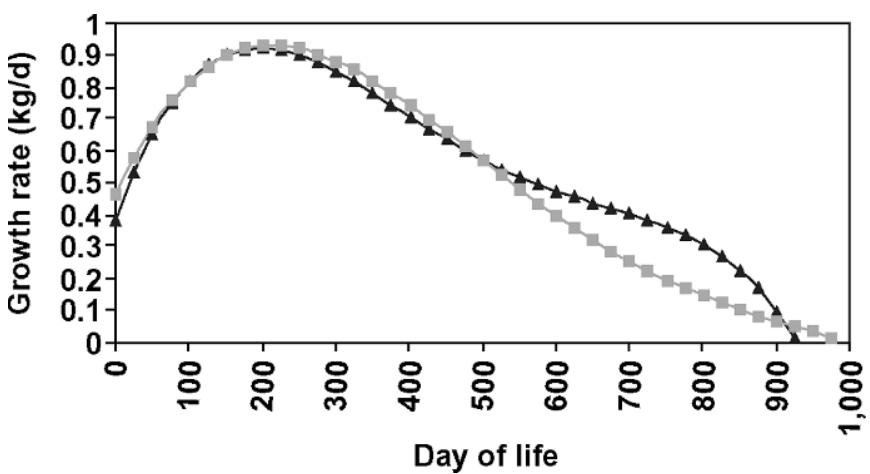

Figure 2. Growth rate for pregnancy-adjusted BW (kg/d) for each day of life from birth to d 1,000 for select $(\boldsymbol{\square})$ and control $(\boldsymbol{\Delta})$ cows.

errors of the heritabilities for PABW and growth rate at selected days of life. These are given in Table 2 and for clarity the heritabilities are plotted in Figure 3. Precalving, the heritability of PABW ranged from 0.41 to 0.59. After first calving, heritability was even higher-ranging from 0.74 to 0.82 - but high heritabilities are expected from the analysis of an experimental herd in which data were well recorded and management was uniform. Coffey et al. (2001) analyzed a subset of the same data and estimated a heritability for PABW during first lactation ranging from 0.56 at 7 DIM to 0.83 around 200 DIM. Coffey et al. (2006) used a multivariate analysis to estimate the heritability of birth weight, weaning weight, and calving weight. Their estimates $(0.53,0.45$, and 0.75 respectively) are consistent with those reported here. Berry et al. (2003) analyzed the BW of first-lactation cows at 60,120 , and 180 DIM and estimated heritabilities of around 0.50. van Elzakker and van Arendonk (1993) also estimated high heritabilities for BW during first lactation (0.75 to 0.86) and Groen and Vos (1995), in an analysis of BW of

Table 2. Heritabilities $\left(\mathrm{h}^{2}\right)$ plus standard errors (SE) at selected days of life for pregnancy-adjusted BW and growth rate

\begin{tabular}{llllll}
\hline & \multicolumn{3}{c}{ BW } & & \multicolumn{2}{c}{ Growth rate } \\
\cline { 2 - 3 } \cline { 5 - 6 } of life & $\mathrm{h}^{2}$ & $\mathrm{SE}$ & & $\mathrm{h}^{2}$ & $\mathrm{SE}$ \\
\hline 0 & 0.58 & 0.078 & 0.80 & 0.052 \\
50 & 0.59 & 0.040 & 0.79 & 0.042 \\
100 & 0.41 & 0.027 & 0.68 & 0.034 \\
200 & 0.66 & 0.032 & 0.78 & 0.030 \\
300 & 0.63 & 0.040 & 0.73 & 0.031 \\
400 & 0.56 & 0.042 & 0.69 & 0.026 \\
500 & 0.50 & 0.040 & 0.75 & 0.017 \\
600 & 0.56 & 0.043 & 0.88 & 0.0084 \\
700 & 0.59 & 0.047 & 0.95 & 0.0041 \\
800 & 0.74 & 0.060 & 0.99 & 0.0010 \\
900 & 0.74 & 0.058 & 0.99 & 0.0006 \\
1,000 & 0.82 & 0.041 & 1.00 & 0.0004 \\
\hline
\end{tabular}




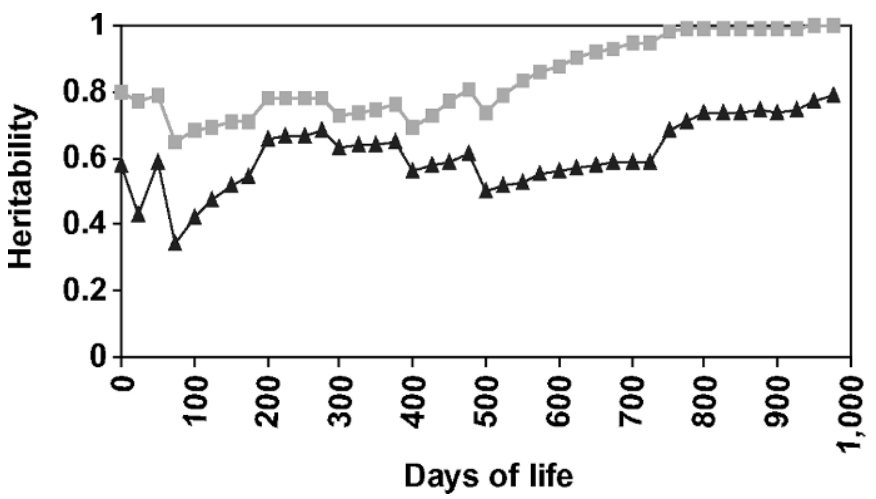

Figure 3. Daily heritability estimates for pregnancy-adjusted BW

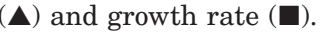

Dutch black and white cattle from birth to first calving, reported heritabilities ranging from 0.41 to 0.64 .

Assuming growth is approximately linear across daily measurements of $\mathrm{BW}$, growth rate can be measured as $\left(\mathrm{w}_{2}-\mathrm{w}_{1}\right) /\left(\mathrm{t}_{2}-\mathrm{t}_{1}\right)$, where $\mathrm{w}=$ weight and $\mathrm{t}=$ time. The contribution of the measurement error to the

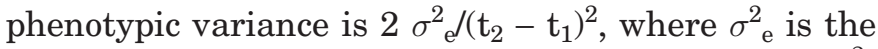
measurement error variance. This varies from $2 \sigma^{2}$ e when $t_{2}-t_{1}=1$, to something negligible when $t_{2}-t_{1}$ is large, resulting in very different heritabilities depending on how the trait is measured. In the present study, the calculation of growth rate assumed that BW measurements (daily solutions from model 1) were taken $1 \mathrm{~d}$ apart. However, other studies have made different assumptions, making comparison of results difficult.

As expected, the heritability of growth rate follows a similar pattern over time to that of PABW, but our estimate is higher than most other estimates in the literature. Berry et al. (2003) reported heritability for BW change between test days of 0.06. van Elzakker and van Arendonk (1993) looked at the average weight gain during early lactation and estimated a heritability of 0.26 for this trait. Groen and Vos (1995) analyzed average daily gain from birth to $50 \mathrm{wk}$ of age and during pregnancy and estimated heritabilities of 0.48 and 0.19 , respectively.

Our estimated heritabilities are very high from around d 600 onwards, with suspiciously low standard errors. Initially, we attempted to model the permanent environment with the same order of orthogonal polynomial as was used to model the genetic effect (a cubic polynomial). Unfortunately, we experienced problems with convergence and so were forced to use a lower order (linear) polynomial. This results in the contribution of the permanent environment to the phenotypic variance of growth rate being a constant value. If we had been able to model the permanent environment with a higher order polynomial, then this term would have increased with increasing days of life, yielding lower heritabilities.

Table 3 has genetic correlations among PABW on selected days of life and the standard errors of these correlations. Correlations were positive, decreasing as the distance between days increased. From first calving onwards, correlations were high. Coffey et al. (2001) also estimated high genetic correlations between PABW on different days of first lactation, the majority of which were greater than 0.90 . Correlations between weights taken before and after first calving were generally low. Genetic correlations of birth weight with weights at other days of life ranged from 0.30 (with $d$ 900 ) to 0.60 (d 50). These results suggest that birth weight is a genetically different trait to weight at all other days, and weight before first calving is a different trait to weight after first calving. This may be due to the additional effect of body lipid mobilization after calving to the cow's overall BW.

Table 4 shows the number of cows that experienced one or more than one incident of a health disorder, and the overall mean incidence of each disorder. Reproductive disorders and other feet problems were experienced by the majority of cows, whereas very few cows were

Table 3. Genetic correlations (above diagonal) between pregnancy-adjusted BW on selected days of life and their standard errors (below diagonal)

\begin{tabular}{llllllllllll}
\hline Day & 0 & 50 & 100 & 200 & 300 & 400 & 500 & 600 & 700 & 800 & 900 \\
\hline 0 & & 0.60 & 0.45 & 0.44 & 0.50 & 0.54 & 0.53 & 0.50 & 0.46 & 0.41 & 0.30 \\
50 & 0.062 & & 0.98 & 0.93 & 0.82 & 0.60 & 0.38 & 0.21 & 0.12 & 0.10 & 0.14 \\
100 & 0.074 & 0.004 & & 0.97 & 0.85 & 0.62 & 0.38 & 0.20 & 0.09 & 0.06 & 0.11 \\
200 & 0.080 & 0.012 & 0.004 & & 0.94 & 0.77 & 0.55 & 0.37 & 0.25 & 0.19 & 0.16 \\
300 & 0.081 & 0.027 & 0.018 & 0.007 & & 0.93 & 0.79 & 0.64 & 0.52 & 0.41 & 0.27 \\
400 & 0.083 & 0.049 & 0.041 & 0.026 & 0.008 & & 0.95 & 0.87 & 0.77 & 0.63 & 0.40 \\
500 & 0.086 & 0.066 & 0.060 & 0.047 & 0.026 & 0.006 & & 0.97 & 0.91 & 0.78 & 0.51 \\
600 & 0.089 & 0.076 & 0.071 & 0.062 & 0.042 & 0.018 & 0.004 & & 0.98 & 0.88 & 0.62 \\
700 & 0.095 & 0.083 & 0.078 & 0.071 & 0.055 & 0.030 & 0.012 & 0.003 & & 0.96 & 0.75 \\
800 & 0.103 & 0.088 & 0.082 & 0.078 & 0.067 & 0.047 & 0.030 & 0.017 & 0.006 & & 0.91 \\
900 & 0.109 & 0.085 & 0.080 & 0.080 & 0.079 & 0.071 & 0.061 & 0.049 & 0.034 & 0.013 & \\
\hline
\end{tabular}


Table 4. Mean incidence and the number of cows with 0,1 , or $>1$ incident of each of the health events ${ }^{1}$

\begin{tabular}{lllrr}
\hline & & \multicolumn{3}{c}{ Frequency } \\
\cline { 3 - 5 } Health event & Mean & 0 & 1 & $>1$ \\
\hline 1. Mastitis & 0.090 & 474 & 34 & 5 \\
2. Other teat & 0.019 & 504 & 8 & 1 \\
3. Reproductive & 0.78 & 294 & 130 & 89 \\
4. Metabolic & 0.10 & 508 & 5 & 0 \\
5. Foul feet & 0.035 & 495 & 18 & 0 \\
6. Lameness & 0.033 & 499 & 11 & 3 \\
7. Other feet & 2.60 & 73 & 65 & 375 \\
\hline
\end{tabular}

${ }^{1}$ Total number of cows is 513 .

diagnosed with a metabolic disorder or teat problems other than mastitis.

A comparison of the results of the different methods of modeling the health disorders showed that the weight and growth measures that explained a significant amount of variation were entirely consistent across models. Therefore, for simplicity, the results of the linear model are presented here.

Table 5 gives heritabilities for the health traits and approximate genetic correlations between health and growth in which the regression coefficient of health on growth was significantly different from zero $(P<0.01)$. Due to the low incidence of metabolic disorders, results for this trait, although significant for birth weight and maximum growth rate, were not included in the table. The correlations presented in Table 5 are functions of the genetic standard deviations of the health events and would be overestimated if the genetic standard deviations were overestimated. Note that a (genetic) regression coefficient that is significantly different from zero translates into a (genetic) correlation coefficient that is significantly different from zero. It therefore seems reasonable to assume that the approximate genetic correlations presented here are significantly different from zero.

All weight traits are expressed in kilograms and all growth rate traits in kilograms per day. Growth at weaning was the only PABW measure to significantly affect mastitis (regression coefficient $=0.512, \mathrm{SE}=$ 0.193). The positive genetic association indicated that cows growing faster at weaning were more prone to mastitis. Increased weight (regression $=0.0183, \mathrm{SE}=$ 0.0053 ) and growth rate (regression $=1.36, \mathrm{SE}=0.394)$ at weaning and increased maximum growth rate (regression $=2.061, \mathrm{SE}=0.689$ ) all contributed to increased feet disorders. There are no similar studies with which to compare these results, but Rauw et al. (1998), in a review on the undesirable effects of selection for high production in farm animals, reported that selection for high BW in broilers has resulted in a correlated negative immune performance. In addition, broilers selected for high BW had a higher mortality $(7.4 \%)$ than broilers selected for low feed conversion (2\%). They also discuss responses in health traits in pigs and report that boars selected for high lean tissue growth rate show significantly more leg weaknesses than nonselected boars.

The only significant negative correlation with health is obtained between weight at calving and reproduction (regression coefficient $=-0.00631, \mathrm{SE}=0.00189)$. Results from this study indicated that cows that were heavier at calving suffered fewer reproductive problems during first lactation. Abdallah and McDaniel (2000) also found that larger cows are more fertile, requiring less time from calving to conception. Conversely, Hansen et al. (1999) and Berry et al. (2003) concluded that heavier cows suffer additional reproductive disorders. Note, though, that the analysis of Hansen et al. (1999) was a phenotypic analysis of a small number of heifers.

Body weight is not routinely collected on the national dairy population and therefore there are few estimates of the heritability of BW at strategic points before and during first lactation. However, research indicates that there is little loss in accuracy if BW is predicted from conformation traits (Koenen and Groen, 1998; Coffey et al., 2003). Coffey et al. (2003) estimated that the correlation between actual and predicted live weight is 0.92 , suggesting that it is entirely feasible to accurately estimate the BW of type-classified heifers at some point during first lactation. Wall et al. (2005) did this and compared sire profiles for BW across the first lactation. They showed differences between sires in BW changes, which may reflect differential rates of maturing.

Tsuruta et al. (2004) showed that genetic parameters for random regressions could be estimated with a ran-

Table 5. Heritabilities of health events and approximate genetic correlations (from statistically significant genetic regression coefficients, $P<0.01$ ) between health events and weaning and calving weights, growth at weaning, and maximum growth rate

\begin{tabular}{llllll}
\hline Health event & $\mathrm{h}^{2}$ & $\begin{array}{l}\text { Weaning } \\
\text { weight }\end{array}$ & $\begin{array}{l}\text { Calving } \\
\text { weight }\end{array}$ & $\begin{array}{l}\text { Growth } \\
\text { weaning }\end{array}$ & $\begin{array}{l}\text { Maximum } \\
\text { growth }\end{array}$ \\
\hline $\begin{array}{l}\text { Mastitis } \\
\text { Reproduction }\end{array}$ & 0.15 & - & - & 0.237 & - \\
Other feet & 0.11 & - & -0.610 & - & - \\
\hline
\end{tabular}


dom regression model using a single observation per animal, with no serious bias. Either BW at a specific day of lactation or growth rate at a specific point during the lactation could therefore be estimated for all animals (cows as well as sires) and included in a selection index both as a trait in its own right and as a predictor of body energy. It is unlikely that routine weighing (or type classification) of young stock would be implemented in the national population due to both the cost and the practical problems associated with such a process. However, these results indicate that there is an association between BW and growth of young stock and health disorders in first lactation. This needs to be considered in the light of current management practices that favor animals that grow faster and mature earlier.

\section{CONCLUSIONS}

This analysis has shown that daily PABW and daily growth rate from birth to the end of first lactation were moderately to highly heritable. Weight at weaning and calving, growth at weaning, and maximum growth rate were genetically correlated with health problems in the first lactation.

\section{ACKNOWLEDGMENTS}

We thank the Scottish Executive Environment and Rural Affairs Department for funding the Langhill Dairy Research Centre, which provided data for this study. This project was funded by Defra, Avoncroft Sires, BOCMPauls, CIS, Cogent, Dartington Cattle Breeding Trust, Genus, Holstein UK, NMR, RSPCA, and SEERAD through the LINK Sustainable Livestock Production Programme. Thanks to Ross McGinn who extracted the data from the database for us and to Ian White and Geoff Pollott for helpful comments.

\section{REFERENCES}

Abdallah, J. M., and B. T. McDaniel. 2000. Genetic parameters and trends of milk fat, days open, and body weight after calving in North Carolina experimental herds. J. Dairy Sci. 83:1364-1370.

Berry, D. P., F. Buckley, P. Dillon, R. D. Evans, M. Rath, and R. F. Veerkamp. 2003. Genetic relationships among body condition score, body weight, milk yield and fertility in dairy cows. J. Dairy Sci. 86:2193-2204.

Brotherstone, S., and W. G. Hill. 1991. Dairy herd life in relation to linear type traits and production. 1. Phenotypic and genetic analyses in pedigree type classified herds. Anim. Prod. 53:279287.

Coffey, M. P., G. E. Emmans, and S. Brotherstone. 2001. Genetic evaluation of dairy bulls for energy balance traits using random regression. Anim. Sci. 73:29-40.
Coffey, M. P., J. Hickey, and S. Brotherstone. 2006. Genetic aspects of growth of Holstein-Friesian dairy cows from birth to maturity. J. Dairy Sci. 89:322-329.

Coffey, M. P., G. Simm, W. G. Hill, and S. Brotherstone. 2003. Genetic evaluation of dairy bulls for daughter energy balance profiles using linear type scores and body condition score analyzed using random regression. J. Dairy Sci. 86:2205-2212.

Coffey, M. P., G. Simm, J. D. Oldham, W. G. Hill, and S. Brotherstone. 2004. Genotype and diet effects on energy balance in the first three lactations of dairy cows. J. Dairy Sci. 87:4318-4326.

Groen, A. F., and H. Vos. 1995. Genetic parameters for body weight and growth in Dutch black and white replacement stock. Livest. Prod. Sci. 41:201-206.

Hansen, L. B., J. B. Cole, G. D. Marx, and A. J. Seykora. 1999 Productive life and reasons for disposal of Holstein cows selected for large versus small body size. J. Dairy Sci. 82:795-801.

Hoffman, P. C., and D. A. Funk. 1992. Applied dynamics of dairy replacement growth and management. J. Dairy Sci. 76:31793187

Kirkpatrick, M., D. Lofsvold, and M. Bulmer. 1990. Analysis of inheritance, selection and evolution of growth trajectories. Genetics 124:979-993

Koenen, E. P. C., and A. F. Groen. 1998. Genetic evaluation of body weight of lactating Holstein heifers using body measurements and conformation traits. J. Dairy Sci. 81:1709-1713.

Mäntysaari, P., M. Ojala, and E. A. Mäntysaari. 2002. Measures of before and after breeding daily gains of dairy replacement heifers and their relationship with first lactation milk production traits. Livest. Prod. Sci. 75:313-322.

Miglior, F., B. L. Muir, and B. J. VanDoormaal. 2005. Selection indices in Holstein cattle of various countries. J. Dairy Sci. 88:1255-1263.

Mourits, M. C. M., A. A. Dijkhuizen, R. B. M. Huirne, and D. T. Galligan. 1997. Technical and economic models to support heifer management decisions: Basic concepts. J. Dairy Sci. 80:14061415.

Pryce, J. E., M. P. Coffey, and S. Brotherstone. 2000. The genetic relationship between calving interval, body condition score and linear type and management traits in registered Holsteins. J. Dairy Sci. 83:2664-2671.

Rauw, W. M., E. Kanis, E. N. Noordhuizen-Stassen, and F. J. Grommers. 1998. Undesirable side effects of selection for high production efficiency in farm animals: A review. Livest. Prod. Sci. 56:15-33.

Tsuruta, S., I. Misztal, Y. J. Lawlor, and L. Klei. 2004. Modeling final scores in US Holsteins as a function of year of classification using a random regression model. Livest. Prod. Sci. 91:199-207.

van Elzakker, P. J. M., and J. A. M. van Arendonk. 1993. Feed intake, body weight and milk production: Genetic analysis of different measurements in lactating dairy heifers. Livest. Prod. Sci. 37:37-51.

Veerkamp, R. F. 1998. Selection for economic efficiency of dairy cattle using information on live weight and feed intake: A review. J. Dairy Sci. 81:1109-1119.

Veerkamp, R. F., J. K. Oldenbroek, H. J. Van Der Gaast, and J. H. J. Van Der Werf. 2000. Genetic correlations between days until start of luteal activity and milk yield, energy balance and live weights. J. Dairy Sci. 83:577-583.

Veerkamp, R. F., and R. Thompson. 1999. A covariance function for feed intake, live weight, and milk yield estimated using a random regression model. J. Dairy Sci. 82:1565-1573.

Visscher, P. M., P. J. Bowman, and M. E. Goddard. 1994. Breeding objectives for pasture-based dairy production systems. Livest. Prod. Sci. 40:123-137.

Wall, E., M. P. Coffey, and S. Brotherstone. 2005. Body trait profiles in Holstein-Friesians modeled using random regression. J. Dairy Sci. 88:3663-3671. 